
CÁLCIO LAMELAR

\title{
INCORPORATION OF THE POLYPHENOLOXIDADE ENZYME IN LAMELLAR CALCIUM PHOSPHATE
}

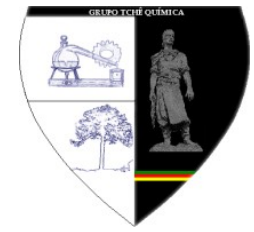

CESÁRIO, Moisés Rômolos ${ }^{1 *}$; BEZERRA, Franciel Aureliano; LIMA, Cícero Bosco Alves de ${ }^{3}$;

${ }^{1}$ Universidade Federal do Rio Grande do Norte, Instituto de Química, Campus Universitário Lagoa Nova, cep 59072-970, Natal - RN, Brasil

(fone: +558432153825 )

2,3 Universidade do Estado do Rio Grande do Norte, Departamento de Química, Rua Almino Afonso, 478, cep 59610-210, Mossoró - RN, Brasil

(fone: +55 8433152235 )

${ }^{*}$ Autor correspondente

e-mail: romolosquimica@hotmail.com

\section{RESUMO}

Received 16 May 2013; received in revised form 20 May 2013; accepted 9 September 2013

A presente investigação trata da produção, purificação e incorporação da enzima polifenoloxidase (PPO), extraída do inhame bruto (Alocasia macrorhiza), em fosfato de cálcio esfoliado com tetrabutilamônio, seguido por um tratamento subsequente com acetato de celulose. O difratograma de raios- $\mathrm{X}$ apresentou um composto de fosfato de cálcio amorfo esfoliado após a adição da solução de enzima. $\mathrm{Na}$ curva termogravimétrica este composto final apresentou perda de massa devido à saída da enzima polifenoloxidase e a partir do espectro de infravermelho foram identificadas as bandas atribuídas às ligações $\mathrm{NH} \mathrm{a} 1550 \mathrm{~cm}^{-1} \mathrm{e} a$ $1600 \mathrm{~cm}^{-1}$. Também bandas em 1040 e $1200 \mathrm{~cm}^{-1}$ está relacionado com estiramento dos grupos fosfato. $\mathrm{O}$ processo de intercalação acontece devido à mudança na cristalinidade do fosfato com a adição de PPO.

Palavras-chave: enzima, polifenoloxidase, fosfato de cálcio.

\section{ABSTRACT}

The present investigation deals the production, purification and incorporation of the enzyme polyphenoloxidase (PPO), from yam crude extracted (Alocasia macrorhiza), on exfoliated calcium phosphate with tetrabutylammonium, it was followed by a subsequent treatment with cellulose acetate. The X-ray diffractogram shows an amorphous exfoliated calcium phosphate compound after adding the enzyme solution. In the thermogravimetric curve this final compound presented also mass losses due to the output of the enzyme polyphenoloxidase and through infrared spectrum were identified the bands assigned to $\mathrm{NH}$ bonds at $1550 \mathrm{~cm}^{-1}$ and at $1600 \mathrm{~cm}^{-1}$. Also bands at 1040 and $1200 \mathrm{~cm}^{-1}$ related to phosphate stretching groups. The intercalation process occurs because of change in crystallinity of the phosphate with the addition of PPO.

Keywords: enzyme, polyphenoloxidase, calcium phosphate. 


\section{INTRODUÇÃO}

A enzima polifenoloxidase (E.C 1.10.3.2) está associada ao escurecimento decorrente da ação da mesma, quando em presença de substratos fenólicos (Murata et al., 1995, Mazzafera et al., 2002, Vieira et al., 1998). Considerando a presença dessa enzima nos vegetais, tais como erva mate, batata, inhame etc, vislumbra-se a possibilidade de extração destas enzimas oxidativas que apresentam potencial de aplicação tecnológica. Algumas publicações indicam uma tendência recente da utilização de tecidos e/ou extratos brutos, em substituição às enzimas purificadas, como na confecção de biossensores e/ou procedimentos de análise, pois são extremamente econômicos e geralmente possuem tempo de vida superior àqueles métodos que utilizam enzimas purificadas. A polifenoloxidase de cogumelos e batatas imobilizadas é usada sobre uma membrana externa de um eletrodo de oxigênio, para determinar substratos fenólicos em águas residuais de cozinhas industriais. Também foi desenvolvido um biossensor para substrato fenólico, utilizando como fonte enzimática o extrato bruto de polifenoloxidase, oriundo de diversos vegetais (Mazzafera et al., 2002, Vieira et al., 1998, King et al., 1980).

Apesar deste cenário, ainda são poucos os métodos enzimáticos descritos que empregam extrato bruto de tecidos vegetais. Atualmente, a biocatálise que consiste na aplicação de enzimas em síntese, representa uma alternativa viável em síntese orgânica para a chamada "química ecologicamente correta" (Química Verde), principalmente pelo controle ambiental. Os métodos enzimáticos convencionais têm sido empregados em meio aquoso, principalmente devido à ideia preconcebida de que este é um bom ambiente, para a manutenção da conformação estrutural da enzima cataliticamente ativa (Mazzafera et al., 2002, Vieira et al., 1998, King et al., 1980, Clément et al., 2005).

Materiais hospedeiros tais como os fosfatos inorgânicos lamelares são excelentes para a imobilização de proteínas e enzimas, pelo fato de apresentarem-se como ótimos trocadores iônicos e são capazes de ligar-se a uma variedade de íons metálicos e a cátions orgânicos nas regiões lamelares. A utilização do estudo da intercalação serve para verificar o comportamento ou a orientação do hóspede dentro do espaço interlamelar. Como os efeitos interativos entre as lamelas dos fosfatos são fracos, a distância entre as mesmas pode ser facilmente aumentada, para proporcionar uma melhor acomodação das moléculas intercaladas (Kim et al., 1993, keller et al., 1994, Suárez et al., 1997, Ogawa et al., 1997, Ferreira et al., 1994). As moléculas hóspedes incluídas, por exemplo, um complexo metálico tris(diimina), ciclodextrina ou enzimas, podem se ligar eletrostaticamente ou por interações de van der Waals, com as lamelas ativadas em ambos os lados. Nessa direção, o composto $\alpha$-fosfato de zircônio, $\mathrm{Zr}\left(\mathrm{HPO}_{4}\right)_{2} \cdot \mathrm{nH}_{2} \mathrm{O}$, abreviado como $\alpha-\mathrm{ZrP}$ é um sólido ácido lamelar que pode ser ativado por reação com uma base, tal como, o íon volumoso n-tetrabutilamônio, $\mathrm{TBA}^{+}$, que é forçado a intercalar por neutralização nos espaços interlamelares ácidos, até formar um coloide permanente (Erlanger et al., 2001, Chen et al., 2001, Chun et al., 2003, Gornael et al., 1949).

A presente investigação trata da afinidade, a organização, a atividade e o potencial natural da fração extraída de inhame que contém a enzima polifenol a ser incorporada no fosfato inorgânico lamelar esfoliado, após a sua ação em acetato de celulose proveniente de filtros de cigarros ("filter tow"), usado como suporte para migração de polifenoloxidase a baixa temperatura (Vieira et al., 1998, Samios et al., 1997).

Dentro deste contexto é importante que se desenvolva novos e eficazes materiais e se conte com metodologias de determinação e quantificação dos diversos tipos de poluentes, com rapidez e seletividade, características encontradas, por exemplo, em sensores químicos ou biossensores (Vieira et al., 1998, Cesário et al., 2011, Bhatia et al., 2010, Calvo et al., 1997, Campanella et al., 1993, Mohammadi et al., 2009).

\section{PARTE EXPERIMENTAL}

Todos os reagentes são de grau analítico, como fosfato de amônio, $\left(\mathrm{NH}_{4}\right)_{2} \mathrm{HPO}_{4}$, cloreto de cálcio, $\mathrm{CaCl}_{2} \cdot 2 \mathrm{H}_{2} \mathrm{O}$, hidróxido de tetrabutilamônio, $\left(\mathrm{C}_{4} \mathrm{H}_{9}\right)_{4} \mathrm{~N}^{+} \mathrm{OH}^{-}$, sulfato de cobre, $\mathrm{CuSO}_{4} \cdot 5 \mathrm{H}_{2} \mathrm{O}$, iodeto de potássio, $\mathrm{KI}$, tartarato de sódio e potássio, $\mathrm{KNaC}_{4} \mathrm{H}_{4} \mathrm{O}_{6} .4 \mathrm{H}_{2} \mathrm{O}$, hidróxido de sódio, $\mathrm{NaOH}$. O inhame (alocassia macrorhiza) foi 
obtido no mercado de Mossoró, RN. O antioxidante utilizado foi o ácido ascórbico. As pontas de cigarros consumidos sem tratamento prévio foram coletadas na cidade de Mossoró, RN. O pirogalol e as soluções foram preparadas em tampão fosfato $0,10 \mathrm{~mol} \mathrm{dm}^{-3} \mathrm{em} \mathrm{pH} \mathrm{7,0}$. Todas as soluções foram preparadas com água destilada.

O procedimento para obtenção dos resultados discutidos neste artigo segue 0 diagrama como mostrado na Figura. 1. Em uma primeira etapa é feita a extração, análise e purificação da polifenoloxidase (PFO) e logo após é feita a síntese de fosfato de cálcio $(\mathrm{CaP})$, sua esfoliação com hidróxido tetrabutilamônio $\left(\mathrm{TBA}^{+} \mathrm{OH}^{-}\right)$, adição da solução enzimática e mistura de fibras de acetato de celulose e finalmente obtenção do material para biossensor.

As medidas da atividade da enzima foram conduzidas usando um espectrofotômetro UV mini 1240 SHIMADZU e as medidas da tensão superficial usando um tensiômetro de Du Nouy.

Os difratogramas de raios $X$ foram obtidos em um difratômetro, modelo XD3A, marca Shimadzu, com velocidade de varredura de $0,030{ }^{\circ} \mathrm{s}^{-1}$, utilizando como fonte de radiação o CuKa $(\lambda=1,54 \mathrm{~nm}$ com $2 \theta$ variando entre 1,5 a $70^{\circ}$ ), voltagem de $2 \mathrm{mV}$, à temperatura ambiente e a distância interlamelar foi calculada usando a Lei de Bragg, a qual estabelece a relação entre o ângulo de difração e a distância entre os planos que a originaram na fase cristalina, dada pela expressão:

$2 d \operatorname{sen} \theta=\mathrm{n} \lambda$

(Eq. 1)

Onde $d$ é o espaço basal e $\theta$ variando é o ângulo de difração para $\mathrm{n}$, um valor inteiro (Lima et al., 2004, Hyuk-Nyun et al., 1997).

Os espectros de absorção na região do infravermelho foram obtidos através do espectrofotômetro de marca Bomem, modelo MB Series, com transformada de Fourier, utilizando pastilhas de $\mathrm{Kbr}$ com $1 \%$ de amostra, na região de 4000 a $400 \mathrm{~cm}^{-1}$, com resolução de $4 \mathrm{~cm}^{-1} \mathrm{e}$ 32 acumulações.

As curvas termogravimétricas foram obtidas em uma termobalança, marca DuPont, modelo 1090, em um intervalo de 300 a $1200 \mathrm{~K}$, com razão de aquecimento de $0,16 \mathrm{~K} \mathrm{~s}^{-1}$, em atmosfera de nitrogênio.

\subsection{Obtenção do extrato bruto de polifenoloxidase}

Para preparar o extrato bruto de PFO, $100 \mathrm{~g}$ do tubérculo de inhame foram homogeneizadas em liquidificador com $200 \mathrm{~cm}^{3}$ de tampão fosfato $0,10 \mathrm{~mol} \mathrm{dm}^{-3}, \mathrm{pH}$ entre 6 e 8 , contendo $10 \mathrm{~g}$ de ácido ascórbico. Utilizou-se ácido ascórbico para diminuir a oxidação da enzima polifenol oxidase durante o processo. A seguir, o material foi filtrado e centrifugado a $6000 \mathrm{rpm}$, durante $60 \mathrm{~min}$. As soluções sobrenadantes foram armazenadas em refrigerador e utilizadas como fonte enzimática na construção de membranas para biossensor (Lima et al., 2004, Hyuk-Nyun et al., 1997, Skladal, 1991, Anderson et al., 1968, Carneiro et al., 2003).

\subsection{Efeitos do pH}

A atividade da enzima foi determinada no intervalo de $\mathrm{pH}$ entre 6 e 8 usando $0,10 \mathrm{~mol} \mathrm{dm}^{-3}$ de tampão fosfato e pirogalol (trifenol) como substrato.

\subsection{Atividade da enzima}

A atividade da enzima foi determinada pela medida de absorbância em $450 \mathrm{~nm}$, da melanina resultante da polimerização da quinona, formada após a reação entre $0,20 \mathrm{~cm}^{3}$ da solução sobrenadante e $2,8 \mathrm{~cm}^{3}$ de solução $0,050 \mathrm{~mol} \mathrm{dm}^{-3}$ de pirogalol em tampão fosfato $0,10 \mathrm{~mol} \mathrm{dm}^{-3} \mathrm{com} \mathrm{pH}$ entre 6 e 8 a $298 \mathrm{~K}$. A atividade enzimática $\left(A_{t}, U / \mathrm{cm}^{3}\right)$ foi calculada a partir da curva de absorbância versus o tempo de reação usando a expressão:

$$
A_{t}=\frac{1000 \Delta_{a b s}}{V \times \Delta t}
$$

Sendo, $V$ o volume da solução resultante (enzima mais pirogalol) $3,0 \mathrm{~cm}^{3}, \Delta \mathrm{t}$ a variação do tempo da reação enzimática e $\Delta$ abs a variação da absorbância da solução da reação observada. Uma unidade de polifenoloxidase (U) é definida como a quantidade de enzima que causa um aumento de 0,0010 na absorbância por min dentro das condições descritas (Eunice et al., 2002).

\subsection{Diálise}

A purificação de uma proteína inicia-se com a liberação do material biológico onde ocorre em órgãos, tecidos ou células isoladas, 
como hemácias, bactérias e leveduras, através do rompimento destas estruturas, que pode ser obtido por metodologias diversas (Gornael et al., 1949, Solomom et al., 1993, Kavrayan et al., 2001). O método de purificação a ser escolhido dependerá da proteína que se pretende isolar, e usualmente, empregam-se combinações sequenciais de diferentes métodos. Frequentemente, o primeiro passo empregado para separação de proteínas de extratos brutos é a precipitação por adição de sais como sulfato de amônio ou solventes orgânicos miscíveis com água. Neste caso a separação baseia-se em diferenças de solubilidade apresentadas pelas proteínas. Na presente investigação, o processo rotineiramente utilizado foi 0 da diálise, que representa um tipo de filtração molecular.

O método do biureto é mais apropriado para proteínas cujas soluções são incolores, ou seja, para proteínas simples não conjugadas. A cor desenvolvida numa reação de íons de cobre em meio alcalino com estas proteínas deve-se unicamente a sua complexação com os nitrogênios das ligações peptídicas e a sua intensidade é proporcional à quantidade de tais ligações (Erlanger et al., 2001, Gornael et al., 1949).

O reagente biureto é composto por $6,0 \mathrm{~g}$ $\mathrm{dm}^{-3}$ de sulfato de cobre, $5,0 \mathrm{~g} \mathrm{dm}^{-3}$ de iodeto de potássio, $18,0 \mathrm{~g} \mathrm{dm}^{-3}$ de tartarato de sódio e potássio, em $0,20 \mathrm{~mol} \mathrm{dm}^{-3}$ de hidróxido de sódio. A solução era preparada semanalmente, armazenada em frasco de polietileno e protegida da luz. Cada medida foi realizada tomando-se seis tubos de ensaio numerados, que receberam solução padrão de polifenoloxidase $0,93 \mathrm{mg} / \mathrm{cm}^{3}$, água destilada para se ter sempre o mesmo volume final e reagente do biureto(14) segundo a Tabela 1.

Os tubos foram agitados para misturar as soluções e encubados ao mesmo tempo em banho-maria a $37^{\circ} \mathrm{C}$, durante $15 \mathrm{~min}$, para que houvesse desenvolvimento de cor. Ao final deste tempo, os tubos foram retirados do banho e o conteúdo de cada um deles transferidos sequencialmente para a cubeta do espectrofotômetro.

Para calcular a concentração da amostra foi usada a expressão (Gornael et al., 1949, Eunice et al., 2002):

$A_{x}=\left(A_{p} / C_{p}\right) \times 1 \times C_{x}$ sendo $A_{p}$ e $A_{x}$ as absorbâncias do padrão e da amostra desconhecida, $C_{p}$ e $C_{x}$ as respectivas concentrações.

\subsection{Síntese do fosfato de cálcio}

O fosfato de cálcio ( $\mathrm{CaP}$ ) foi sintetizado adicionando-se lentamente uma solução diluída de cloreto de cálcio diidratado a uma solução de fosfato de fosfato de amônio dibásico e aquecida a $363 \mathrm{~K}$ (keller et al., 1994, Lima et al., 2004). O composto obtido foi esfoliado com soluções de hidróxido de tetrabutilamônio $(\mathrm{TBA}+\mathrm{OH}-)$. Nessa operação CAP foi titulado com solução $0,50 \mathrm{~mol}$ $\mathrm{dm}^{-3}$ de $\mathrm{TBA}^{+} \mathrm{OH}^{-}$em $\mathrm{pH} 8,0$ até obter uma suspensão (Calvo et al., 1997). Fez-se logo em seguida, a incorporação da enzima polifenoloxidase às lamelas do CAPesf, misturando-se $10,0 \quad \mathrm{~cm}^{3}$ de extrato bruto enzimático à $0,50 \mathrm{~cm}^{3}$ da suspensão do esfoliado e obtivemos uma mistura denominada como EnzCAPesf (Solomom et al., 1993, Kavrayan et al., 2001, Zaia et al., 1998, Azevedo et al., 2005).

\subsection{Reaproveitamento de Fibras de Cigarro}

A polpa de filtros de acetato de celulose sem prévio uso foi preparada em liquidificador por desagregação em água. Em seguida essa polpa foi banhada com a mistura do extrato bruto enzimático e fosfato esfoliado durante dois dias com filtração posterior. Um sólido branco foi obtido e o utilizaremos futuramente como material para biossensor.

\section{RESULTADOS E DISCUSSÃO:}

As dificuldades inerentes à purificação e à multiplicidade que elas exibem contribuem para a falta de progresso em definir a estrutura dessa proteína. Na ausência de cristais suficientemente puros para análise cristalográfica por raios $\mathrm{X}$, a estrutura sólida das proteínas permanece indefinida. Do ponto de vista estrutural, a polifenoloxidase é uma enzima que contém dois íons cobre como sítios ativos e, portanto, podem ser determinado pelo clássico método do biureto (Mazzafera et al., 2002, Chun et al., 2003, Gornael et al., 1949, Solomom et al., 1993). Apesar da toxidade dos fenóis e seus derivados, devidos às atividades industriais, alguns resíduos relacionados com a intensa produção vem de plásticos, corantes, tintas, detergentes, 
desinfetantes, refinaria de petróleo e principalmente de papel e celulose. As pesquisas com tecidos vegetais de um modo geral utilizam fenóis como substratos, daí o emprego do pirogalol. Assim, a polifenoloxidase (PFO) catalisa a oxidação de fenóis pelo oxigênio molecular com produção de quinonas, cuja polimerização forma melaninas. O decréscimo da concentração de oxigênio nas reações enzimáticas é inversamente proporcional às concentrações dos substratos fenólicos. Assim, os fenóis (pirogalol, catecol, fenol e p-cresol) podem ser dosados diretamente em soluções com essa enzima. A massa molar das polifenoloxidades varia de 57 a $62 \mathrm{kDa}$, com exceção da PFO do cogumelo que apresenta $128 \mathrm{kDa}$, possuindo duas cadeias maiores com massas de 43-45 kDa, onde estão os sítios ativos e duas menores com $13 \mathrm{kDa}$ cada. O cobre binuclear pertencente às unidades acopladas antiferromagneticamente, situadas próximo ao sítio ativo, capazes de se ligar ao dioxigênio para formar um complexo dioxigêniodicobre (II).

Com base na atividade enzimática em função do $\mathrm{pH}$ cujo valor máximo descrito na literatura é aproximadamente em pH 7,0,(Vieira et al., 1998, Cesário et al., 2011, Anderson et al., 1968, Carneiro et al., 2003) analisou-se a concentração da enzima da amostra estudada, cujos resultados são apresentados na Figura 2. Com base na absorbância de 0,156 determinado para a amostra desconhecida, o valor de Cx foi calculado e foi igual a $0,43 \mathrm{mg} \mathrm{cm}^{-1}$. Por outro lado, para a concentração padrão o valor encontrado foi $0,93 \mathrm{mg} \mathrm{cm}^{-1}$ relacionada com a absorbância correspondente a 0,33.

O hidrogenofosfato de cálcio é um sólido cristalino que quando titulado com o agente esfoliante favorece a neutralização e possibilita a intercalação do cátion tributilamônio $\left(\mathrm{TBA}^{+}\right)$, devido à reação do grupo hidroxila livre da superfície do fosfato à lamela que fica com carga negativa. Neste processo, o sólido deve ter uma composição $\left.\mathrm{Ca}\left(\mathrm{H}_{2} \mathrm{PO}_{4}\right)\left[\mathrm{TBA}^{+}\right)_{2} \mathrm{PO}_{4}\right] \cdot \mathrm{H}_{2} \mathrm{O}$ que disperso em água forma um coloide branco, com a esperada separação das lamelas. Devido à baixa densidade de carga, os íons $\mathrm{TBA}^{+}$serão deslocados quantitativamente por cátions de maior densidade de carga, ou seja, é um bom grupo lábil para as reações de intercalação posterior (keller et al., 1994, Hyuk-Nyun et al., 1997).
A distância basal do fosfato de cálcio de 697 pm aumenta para 1514 pm quando intercalado, como mostrado nas Figuras. 3a e $3 \mathrm{~b}$, respectivamente. Porém, a existência do pico basal intenso e fino indica uma excelente cristalinidade do composto. Esse fato é esperado porque $0 \mathrm{TBA}^{+}$possui uma distância próxima a 1000 pm. Por outro lado, quando ao composto foi adicionado à suspensão enzimática de polifenoloxidase observou-se perda de cristalinidade (Burton, 1994, Machlan et al., 1990, Clearfield et al., 1995) como pode ser visto na Figura 3c. A mistura composta de fosfato-TBApolifenol não produz qualquer precipitado, no entanto, quando o acetato de celulose é adicionado há formação, e é justamente o material para biossensor. Isto ocorre devido ao fato do éster acetato de celulose conter grupos químicos capazes de ligar-se a $\mathrm{PO}_{4}{ }^{3-} \mathrm{TBA}^{+}$. Assim a enzima está envolvida nesse sistema entre os grupos fosfato-acetato que foram estabilizados pelo crosslinking bifuncional devido à presença de vários grupos. Da mesma forma, a enzima foi estabilizada nesse sistema crosslinking com o mesmo conjunto de grupos ativos bifuncionais. A solução enzimática pode conter na sua estrutura, além de íons cobre, grupos fenila, oxigênio, nitrogênio e também resíduos de aminoácidos que consistem em grupos ionizáveis e/ou grupos hidrofóbicos com reatividade química variável. Associado a isso é possível a existência de pelo menos uma região da macromolécula chamado de "campo" com características hidrofóbicas. Esses resíduos de aminoácidos e/ou domínios podem participar da interação da enzima com o suporte por ligações fracas (adsorção) ou covalentes simples ou covalentes crosslinking (Erlanger et al., 2001, Chen et al., 2001). Considerando a afinidade dos grupos que constituem a cadeia polimérica do acetato de celulose com água, conclui-se que os grupos hidrofóbicos acetil e os grupos hidrofílicos hidroxila podem formar ligações de hidrogênio com a água, e interagir com o fosfato para formar acetil-fosfato, como mostrado na Figura 1. Tal como sugerido pelo difratograma final apresentado na Figura 3c, a formação de um composto amorfo ocorreu após a mistura com o substrato enzimático. Esse comportamento indica que a enzima deve ser inserida dentro da cavidade interlamelar, gerando um largo pico (Yamauchi et al., 2004). Este processo provoca uma variação na tensão superficial da água, como mostrado pelos valores constantes na 
Tabela 2 e também apresenta uma diminuição quando a enzima é intercalada.

Tabela 2. Tensão superficial (TS) e densidade (d) das amostras envolvendo a enzima no fosfato de cálcio (EnzCaPesf)

\begin{tabular}{c|c|c}
\hline Amostras & $\mathbf{T S}\left(\mathbf{m N ~ m}^{-1}\right)$ & $\mathbf{d}\left(\mathbf{g ~ d m}^{-3}\right)$ \\
\hline EnzCaPesf & $20,9 \pm 0,05$ & 779 \\
$\mathrm{H}_{2} \mathrm{O}$ & $70,0 \pm 0,05$ & 990 \\
\hline
\end{tabular}

O efeito da reação de fosfato de cálcio com hidróxido de tetrabutilamônio é mostrado na Figura 4. Uma banda muito intensa e larga em $3404 \mathrm{~cm}^{-1}$ atribuída ao modo de estiramento vibracional de grupos $\mathrm{OH}^{-}$e de moléculas de água coordenadas à estrutura do fosfato de cálcio. A presença de duas bandas em 2989 e $2866 \mathrm{~cm}^{-1}$ deve corresponder ao estiramento C$\mathrm{H}$. As bandas características do grupo fosfato aparecem em 1057 e $1025 \mathrm{~cm}^{-1}$ e ao estiramento simétrico da ligação P-O em $889 \mathrm{~cm}^{-1}$.

Analisando o espectro da Figura 5, após a enzima ser introduzida na matriz inorgânica lamelar se identificam as bandas: a) em $1550 \mathrm{~cm}$ ${ }^{1}$ e em $1600 \mathrm{~cm}^{-1}$ atribuídas às ligações $\mathrm{N}-\mathrm{H}, \mathrm{b}$ ) em 1400-1500 $\mathrm{cm}^{-1}$ características de estiramentos $\mathrm{C}=\mathrm{C}$ (aromático), c) em $1730 \mathrm{~cm}^{-1}$ relativa a $\mathrm{C}=\mathrm{O}$ ou efeito de conjugação similar a $\mathrm{C}=\mathrm{N}$ e d) em $1040 \mathrm{~cm}^{-1}$ e outra em $1200 \mathrm{~cm}^{-1}$ dos estiramentos relacionados ao fosfato. Nota-se que há, portanto, reações de grupos funcionais específicos da enzima com substrato e não existe qualquer banda que possa ser atribuída ao modo de estiramento vibracional de grupos $\mathrm{OH}$ e de molécula de água (Lima et al., 2004, Yamauchi et al., 2004, Zang et al., 1996, Göni et al., 1996).

A evidência da enzima no sobrenadante após o processo de adsorção foi monitorada por espectrofotometria de ultravioleta-visível (HyukNyun et al., 1997). A diferença de absorção, em comparação com a solução original sugere absorção parcial ou incorporação da enzima na estrutura inorgânica. Outra prova do sucesso desta operação é demonstrada através de estudos térmicos do fosfato de cálcio com hidróxido de tetrabutilamônio, como mostrado na Figura 6.

Este composto apresentou uma perda de massa constante na curva termogravimétrica, no intervalo de 323 a $523 \mathrm{~K}$, demonstrando que o fosfato de cálcio decompõe-se quando se aumenta a temperatura. Comportamento semelhante também foram observado quando a enzima foi incorporada ao composto lamelar. $\mathrm{Da}$ mesma forma, a curva térmica diferencial mostra a mesma decomposição para chegar também ao resíduo de 10 \% (Bideau et al., 1993).

\section{CONCLUSÕES:}

A enzima polifenoloxidase extraída do inhame apresenta uma atividade de $860 \mathrm{U} / \mathrm{mg}$

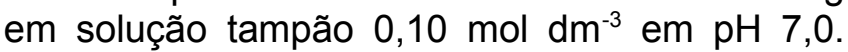
Forma-se uma solução coloidal esbranquiçada quando intercalada com $\mathrm{TBA}^{+} \mathrm{OH}^{-}$. A enzima polifenoloxidase quando sorvida pelas lamelas do fosfato de cálcio provoca um aumento na absorbância, o que sugere uma parcial sorção ou incorporação. Os resultados aqui obtidos confirmam o que já se propunha anteriormente em relação à polifenoloxidase. Dessa forma, abrise uma nova perspectiva de trabalho com membranas.

Considerando a concentração em função da absorbância, através do método do biureto da amostra desconhecida $\mathrm{C}_{\mathrm{x}}$ pode-se calcular o teor de enzima $0,43 \mathrm{mg} \mathrm{cm}^{-3}$ para uma absorbância de 0,156 , o que se compara com a concentração do padrão $0,93 \mathrm{mg} \mathrm{cm}^{-3}$ para uma absorbância de 0,33 . No processo de intercalação acontece mudança na cristalinidade do fosfato com a adição da polifenoloxidase, como se comprova pela presença de bandas $\mathrm{C}-\mathrm{C}$ e $\mathrm{PO}_{4}$ nos espectros na região do infravermelho, como também demonstram as perdas de massa referente à fração orgânica. Na mistura de enzima com composto intercalado obtém-se um material branco, rígido e sólido, o qual lembra muito bem uma membrana enzima-fosfato ou material para biossensor, o qual será objeto de estudo futuro.

\section{AGRADECIMENTOS:}

Agradecemos ao PIBIC- UERN e ao CNpq pelo apoio financeiro à pesquisa.

\section{REFERÊNCIAS:}

1. Anderson, R.A., Sowers, J.A, Phytochemistry, 1968, 7, 293.

2. Azevedo, H.S., Leonor, I.B., Alves, C.M., Reis, R.L. Mater. Sci. Eng, 2005, 25, 169.

3. Bhatia, R.B., Brinker, C.J., Grupta, A.K., 
Singh, A.K. Chem. Mater, 2010, 12, 2434.

4. Bideau, J.L., Bujoli, B., Jouanneaux, A., Payen, C., Palvadeaum, P., Rouxel, J. Inorg. Chem, 1993, 32, 4617.

5. Burton, S.G. Catal. Today, 22 (1994) 459.

6. Calvo, E.J., Danilowicz, C. J. Braz. Chem. Soc, 1997, 8, 563.

7. Campanella, L., Beone, T., Sammartino, M.P., Tomassetti, M. Analyst, 1993,118, 979.

8. Carneiro, C.E.A, Rolim, H.M.V.K., Fernandes, F.K. Acta Sci. Biol. Sci, 2003, 25, 189.

9. Cesário, M.R., Moura, D.M.A., Macedo, D.A.; Lima, C.B.A. Tchê Química, 2011, $8,41$.

10. Chen, R.J., Zhanh, Y., Wang, D., Dai, H., J. Am.Chem. Soc, 2001, 123, 3838.

11. Chun, O.K., Kim, D., Moom, H.Y, Kang, G.H., Lee, C.Y. J. Agric. Food Chem, 2003, 51, 7240.

12. Clearfield, A., Wang, J.D., Tian, Y., Stein, E., Bhardwaj, C. J. Solid State Chem, 1995, 117, 275.

13. Clément, S., Beatriz, J., Philippe, B., Michael, P. J. Mater. Chem, 2005, 15, 3559.

14. Erlanger, B.F., Chen, B.-X., Zhu, M., Brus, L. Nano Lett, 2001, 1, 465.

15. Eunice, F.S.V., Cestari, A.R., Alisson, J.P.N., Marina, M.S.F., Airoldi, C. J. Braz. Chem. Soc, 2002, 13, 260.

16. Ferreira, M., Cheung, M.J.H., Rubner, M.F. Thin Solid Films, 1994, 244, 985.

17. Göni, A., Rius, J., Insausti, M., Lezama, L.M., Pizarro, J.L., Arriortua, M.I.,; Rojo, T. Chem. Mater, 1996, 8, 1052.

18. Gornael, A.G., Bardwill, C.J., David. M.M. J. Biol. Chem, 1949, 177, 751.

19. Hyuk-Nyun, K., Keller, S.W., Thomas, E.M. Chem. Mater, 1997, 9, 1414.

20. Kavrayan, D., Aydemir, T. Food Chem, 2001, 74, 147.

21. Keller, S.W., Kim, H.-N., Mallouk, T.E. J. Am. Chem. Soc, 1994, 116, 8817.

22. Kim, R.M., Pillion, J.E., Burwell, D.A., Groves, J.T., Thomson, M.E. Inorg. Chem, 1993, 21, 4509.

23. King, W.P., Joseph, K.T, Kissinger, P.T, J. Assoc. of Anal. Chem, 1980, 63, 137.

24. Lima, C.B.A., Airoldi, C. Solid State Sci, 2004, 6, 1245.

25. Machlan, D.J., Morgan, K.R. J. Phys. Chem, 1990, 94, 7656.
26. Mazzafera, P., Gonçalves, K.V., Shimizu, M.M. Sci. Agric, 2002, 59, 695.

27. Mohammadi, A., Moghadam, A.B., Dinarvand R., Rezaei-Zarchi, S. Int. J. Electrochem. Sci, 2009, 4, 895

28. Murata, M., Tsurutani, M., Tomita, M., Homma, S., Kaneko, K. J. Agric. Food Chem, 1995, 43, 1115.

29. Ogawa, M., Kuroda, K. Bull. Chem. Soc. Jpn, 1997,70, 2593.

30. Samios, E., Dart, R.K. Dawkins, J.V. Polymer, 1997, 38, 3045.

31. Skladal, P., Collect. Czech. Chem. Commun, 1991, 56, 1427.

32. Solomom, E.I., Lowery, M.D. Science, 1993, 259, 1575.

33. Suárez, M., Rodríguez, M.L., Llavona, R., Barcina, L.M., Veja, A., Rodríguez, J. J. Chem. Soc, Dalton Trans. 1997, 16, 2757.

34. Vieira, I.C., Fatibello-Filho, O. Anal. Chim. Acta, 1998, 366, 111.

35. Yamauchi, K., Goda, T., Takcucchi, N., Einaga, H., Tanabe, T. Biomaterials, 2004, 25, 5481.

36. Zaia, D.A.M., Zaia, C.T.B.V., Lichting, J. Quim. Nova, 1998, 21, 787.

37. Zang, B., Poojary, D.M., Clearfield, A. Chem. Mater, 1996, 8, 1333. 
Tabela 1. Método do biureto com amostras em tubos de ensaio (Tub) para quantificação da PPO em volume da amostra desconhecida (Vdes), tenho o volume da solução padrão (Vpad) $0,93 \mathrm{mg} \mathrm{cm}^{-3}$, com adição de volume de água (Vag), sempre com um volume de reagente do biureto de $2,5 \mathrm{~cm}^{-3}$

\begin{tabular}{c|c|c|c}
\hline Tubo & $\begin{array}{c}\text { Vpad/mg } \\
\mathbf{c m}^{-3}\end{array}$ & $\begin{array}{c}\text { Vdes/mg } \\
\mathbf{c m}^{-3}\end{array}$ & $\mathbf{V a g} / \mathbf{c m}^{-3}$ \\
\hline 1 & --- & --- & 1,5 \\
2 & 0,10 & 0,10 & 1,4 \\
3 & 0,20 & 0,20 & 1,3 \\
4 & 0,40 & 0,40 & 1,1 \\
5 & 0,70 & 0,70 & 0,8 \\
6 & 1,00 & 1,00 & 0,5 \\
\hline
\end{tabular}

$1^{2}$ passo

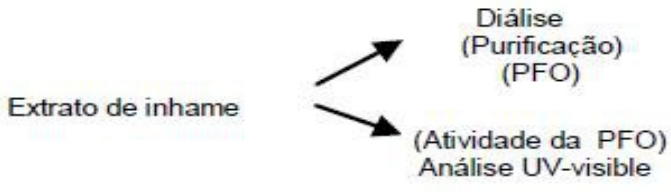

$2^{\circ}$ passo

Fosfato de

Cálcio (CaP)
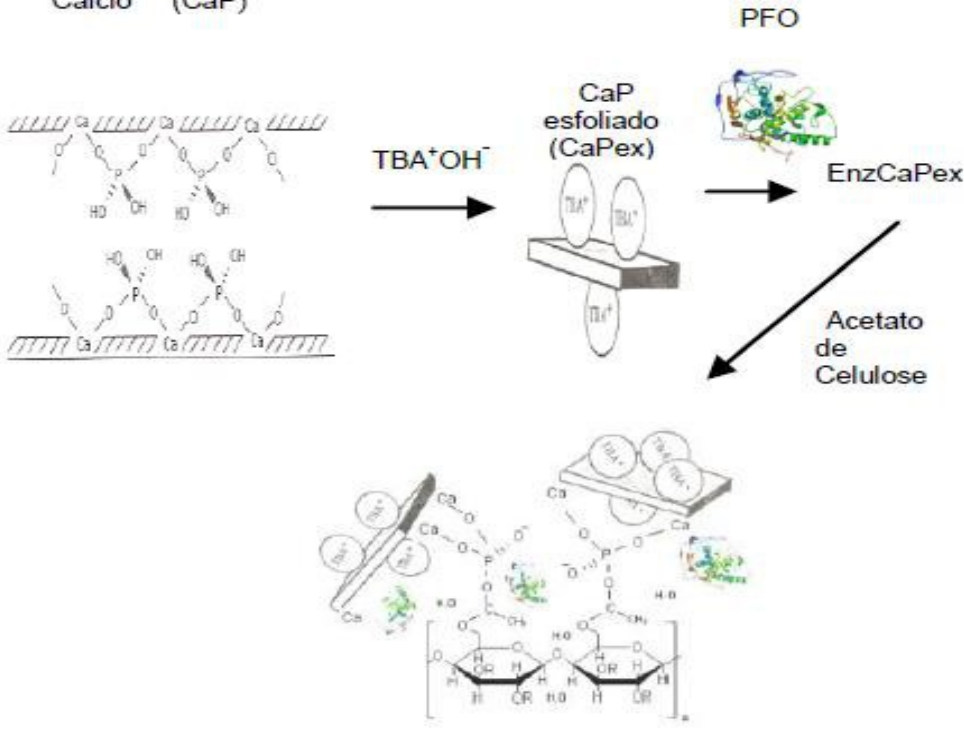

Figura 1. Passos na obtenção do material para biossensor.

PERIÓDICO TCHÊ QUÍMICA • www.periodico.tchequimica.com • Vol. 10/11 N. 20/21. - ISSN 1806-0374 (impresso) • ISSN 1806-9827 (CD-ROM) • ISSN 2179-0302 (meio eletrônico) 


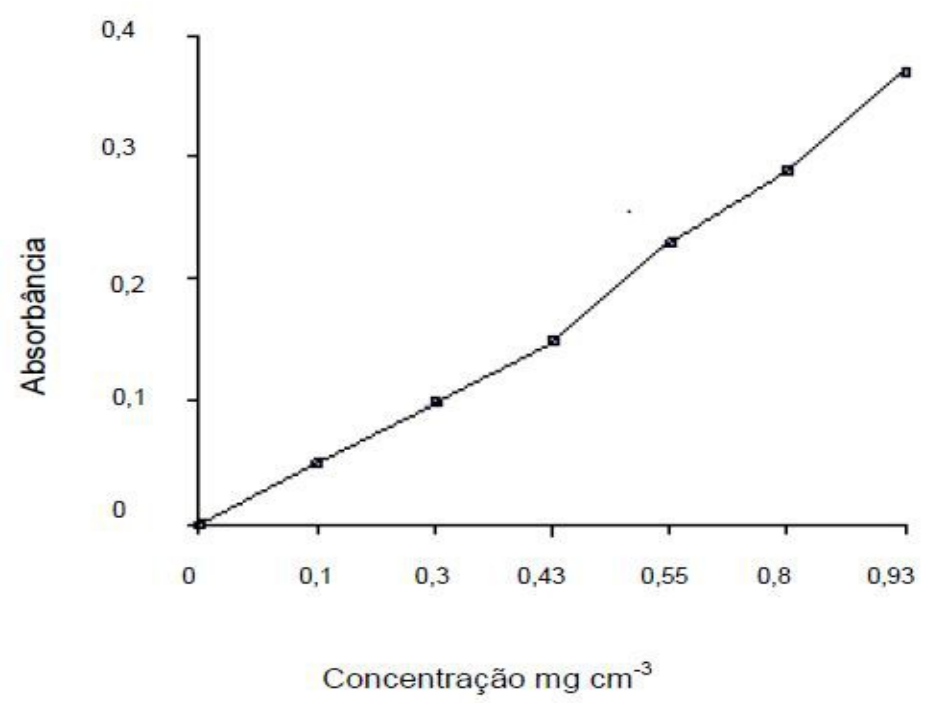

Figura 2. Concentração da PFO na amostra em estudo.

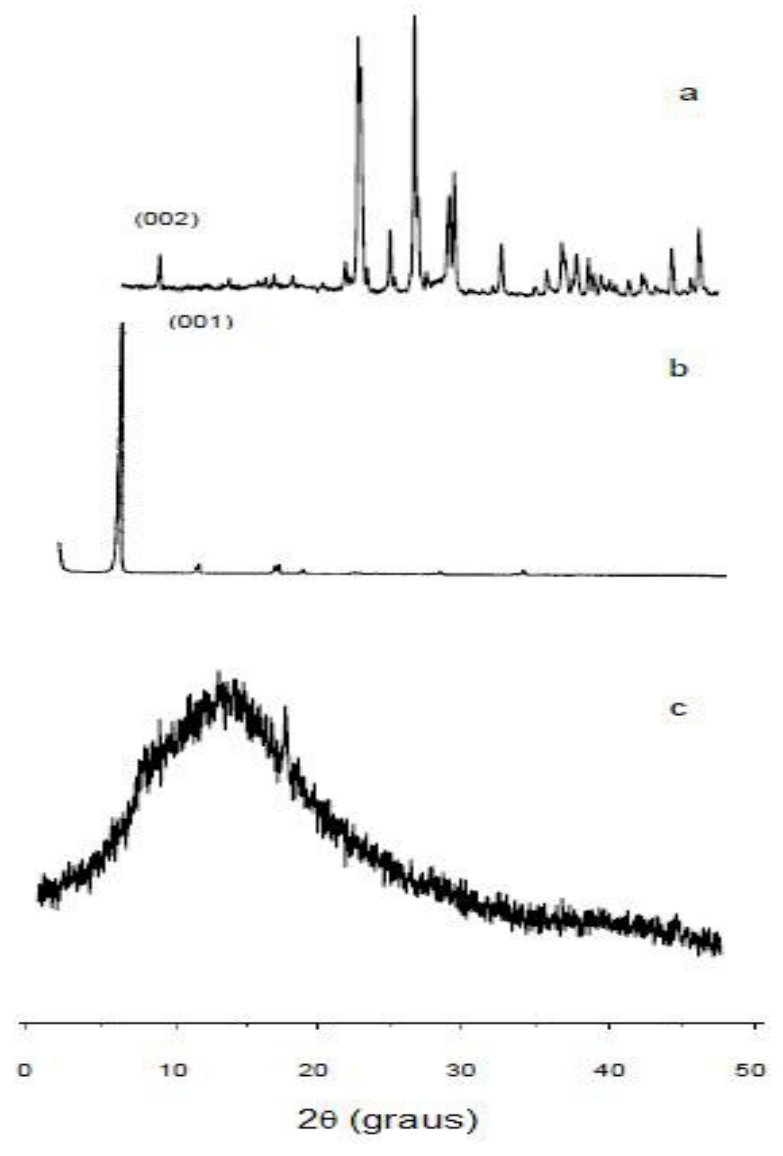

Figura 3. Difratograma de raios-X do fosfato de cálcio (a), na forma esfoliada (b) e fosfato de cálcio esfoliado após reação com a mistura de extrato bruto da polifenoloxidase e da polpa de filtros de acetato de celulose (c) 


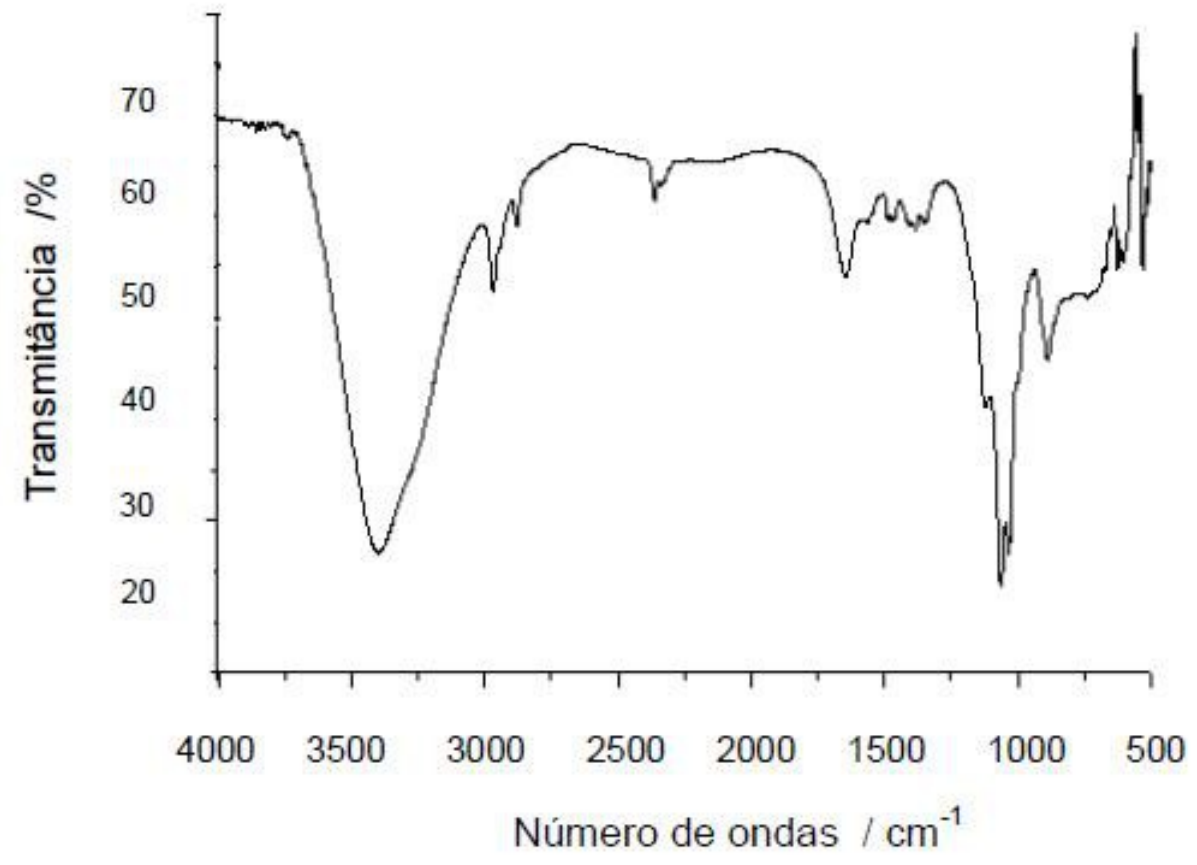

Figura 4. Espectro infravermelho do fosfato de cálcio após reação com o $\mathrm{TBA}^{+} \mathrm{OH}^{-}$

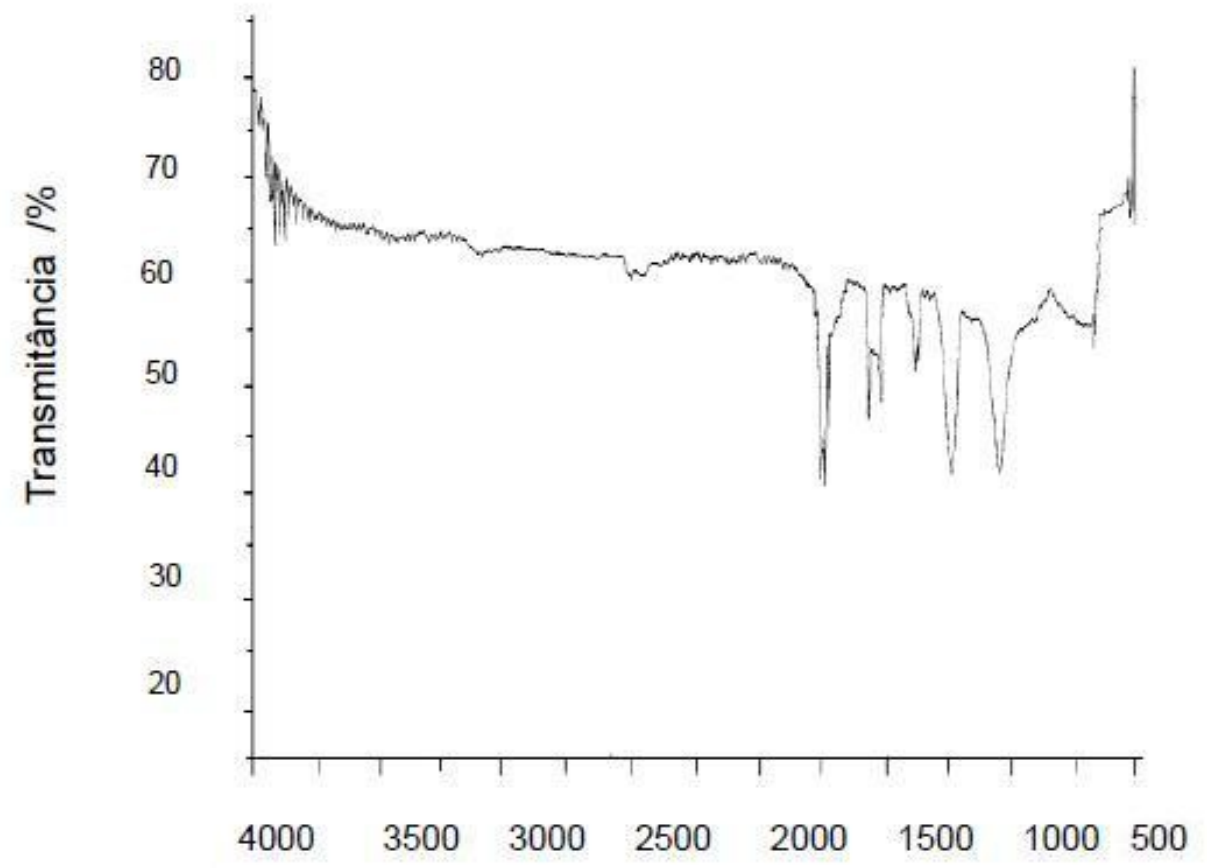

Número de ondas/ $\mathrm{cm}^{-1}$

Figura 5. Espectro infravermelho do fosfato de cálcio após reação com o substrato enzimático. 


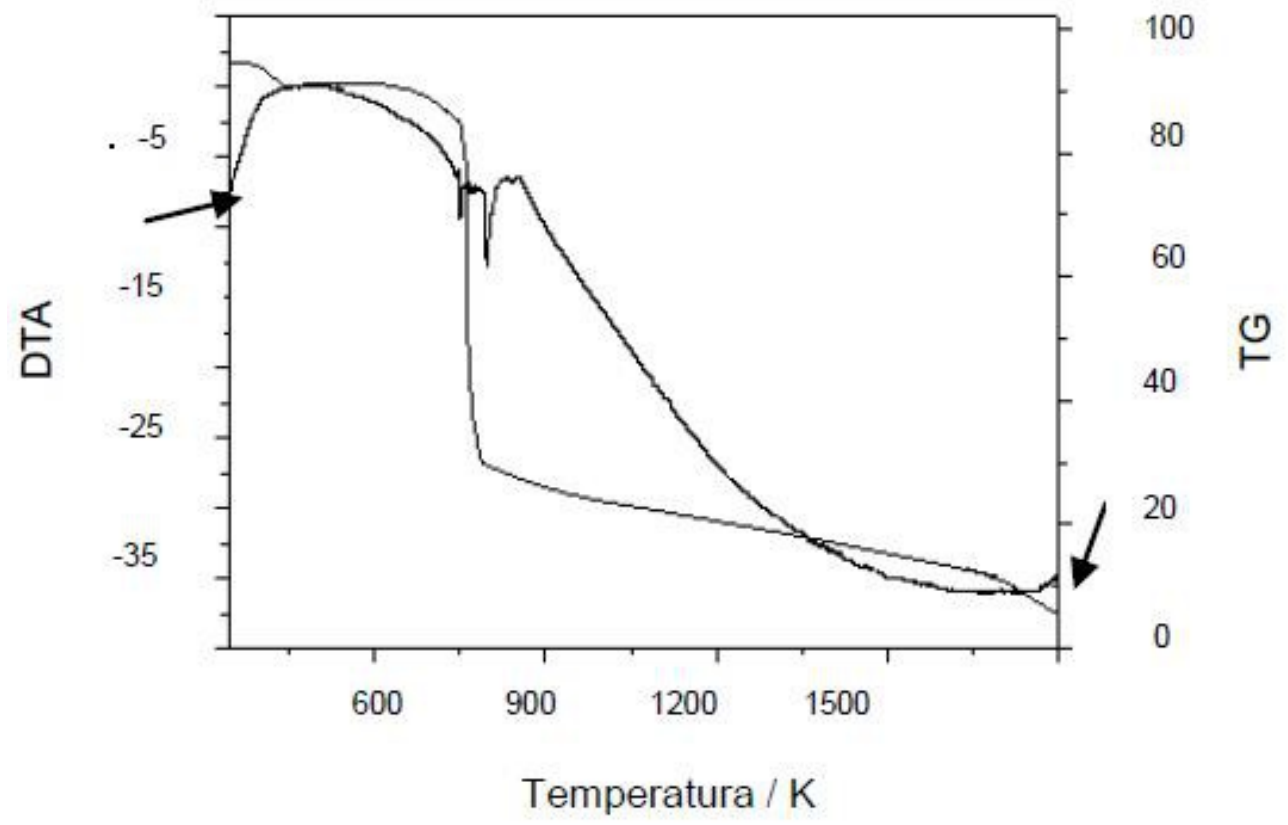

Figura 6. Curva termogravimétrica (TG) e análise térmica diferencial (DTA) do fosfato de cálcio tratado com a enzima.

PERIÓDICO TCHÊ QUÍMICA • www.periodico.tchequimica.com • Vol. 10/11 N. 20/21 • ISSN 1806-0374 (impresso) • ISSN 1806-9827 (CD-ROM) • ISSN 2179-0302 (meio eletrônico)

OPEN ACCESS. This article is licensed under a Creative Commons Attribution 4.0 (CC BY 4.0) International License, which permits use, sharing, adaptation, distribution, and reproduction in any medium or format, as long as you give appropriate credit to the original author(s) and the source, provide a link to the Creative Commons license, and indicate if changes were made. The images or other third-party material in this article are included in the or exceeds the permitted use, you will need to obtain permission directly from the copyright holder. To view a copy of this license, visit http://creativecommons.org/licenses/by/4.0/. To view a copy of this license, visit http://creativecommons.org/licenses/by/4.0/. 